\title{
Demonstrating the Impact of International Collaborative Disciplinary Experiences on Student Global, International, and Intercultural Competencies
}

\author{
Rob Elliott, M.S. \\ Computer and Information Technology \\ Indiana University Purdue University Indianapolis (IUPUI) \\ Indianapolis, Indiana \\ elliott@iupui.edu
}

\author{
Xiao Luo, Ph.D. \\ Computer and Information Technology \\ Indiana University Purdue University Indianapolis (IUPUI) \\ Indianapolis, Indiana \\ luo25@iupui.edu
}

\begin{abstract}
This Work in Progress research paper describes a study that directly compares the impact of a globally themed Information Technology (IT) project on students' global, international, and intercultural (GII) competencies. The authors will compare the change in student competencies by analyzing the impact of a common project with an international theme integrated into three different undergraduate IT classroom modalities: (1) a traditional classroom course with no interaction with students from a foreign university, (2) a virtual exchange context where teams of local students and students from a foreign university collaborate via information and communication technologies (ICT), and (3) a hands-on version of the course project that is implemented by local and remote students collaborating at a foreign university during a short-term study abroad program.

This paper directly compares the changes in student GII competencies after executing the classroom project in the first and third modalities: a classroom without international collaboration and in conjunction with students at a foreign university during a short-term study abroad program. Preliminary results suggest that student competencies are more significantly improved when students collaborate with their international peers. However, the results might be influenced by the demographic profiles of students in the various courses. Students who pursue opportunities to study abroad may already have an innate expectation or desire to improve their GII competencies.
\end{abstract}

Index Terms-global learning, collaborative learning, STEM, STEM education

\section{INTRODUCTION}

Global industries such as Information Technology (IT) are actively building a workforce of professionals who can demonstrate global, international, and intercultural (GII) competencies in addition to their disciplinary expertise. Higher Education Institutions (HEIs) are responding to this and other concerns by implementing a broad swath of internationalization initiatives into their strategic plans and curricula. By far, the most visible effect of these efforts for students is related to student mobility - and most often with the vehicle of shortterm study abroad programs [1]. However, most estimates show that fewer than $5 \%$ of undergraduate students can or are willing to take advantage of study abroad opportunities
[1]. The study abroad participation rate for students in the program in this study is a mere $3 \%$ [2].

A variety of globalization initiatives have attempted to widen the availability of globally themed programming to students in HEIs without the need to leave their campuses [3], [4], [5]. Programs resulting from these initiatives have been shown to have some impact on student GII competencies but have not been directly compared to the student outcomes from study abroad programs. Furthermore, many internationalization programs are interdisciplinary, thus impeding efforts to include disciplinary content into the programming.

This study proposes the direct comparison of a globallythemed IT project built into three different undergraduate IT classroom contexts: a project with an international focus and no interaction with students from a foreign university, the same project executed in teams of local students and students from a foreign university who collaborate via information and communication technologies (ICT) in a virtual exchange, and a hands-on version of the course project that is implemented by local and remote students collaborating at a foreign university during a short-term study abroad program. This work in progress paper is the first foray into this work and compares populations in the first and third modalities only.

We want to determine if such internationally themed projects improve student GII competencies, and examine any differences in those outcomes when compared to the classroom context in which the project is executed. Discovering that significant positive impacts can be made in modalities other than study abroad programs could lead to additional research and funding of alternative collaborative opportunities for students. Doing so might make international engagement opportunities available to the broad swath of students who are currently unable or unwilling to engage in study abroad programs.

\section{RELATED WORK}

For decades, institutions of higher education have worked to ensure that their curriculum provides ample opportunities for 
student engagement across international borders. Curriculum internationalization comes in many forms. Qiang defines four types of approaches implemented by institutions: the activity approach, the competency approach, the ethos approach, and the process approach [6, pp. 250-251]. Of these four approaches, the two that are most relevant at the individual faculty and course level are competency (which looks toward improvements in the skills, knowledge, attitudes, and values in students and faculty) and process (that advocates integration of international and intercultural aspects into the universities' traditional roles.) These are, however, not without their challenges. Qiang specifically states that "...there is an urgent need for further applied research to identify those competencies which help students to be successful national and international citizens and to contribute to local and global work environments" (p. 250). A concern of the process approach relates to the sustainability of the international aspects infused into the curriculum. The conclusion is that any undertaking must be able to be continuously offered and widely available to students.

While many curricula include requirements for courses related to "cultural understanding" and similar subjects, these courses are often generalized and available to students of any major. It is quite possible that the infusion of international dimensions directly into the courses relevant to the students' disciplines could result in even higher global, international, and intercultural (GII) competencies. The Higher Education Academy in the UK goes so far as to explicitly recommend that institutions "(b)uild-in experiential learning so that students can experience and reflect on the intercultural aspects of their learning alongside the core disciplinary learning" [7]. Yet at many institutions there appear to be few opportunities for STEM students to engage in discipline-specific projects with peers from international institutions.

The most visible aspect of an internationalized curriculum is the ability for students to participate in study abroad programs. The positive impact of even a short-term study abroad on student global, international, and intercultural (GII) competencies has long been established [8][9]. However, study abroad is limited to a very small subset of students with ample financial means and/or institutional support. The HEI focus on student mobility disenfranchises the rest of the student population who cannot or will not study abroad during their undergraduate career. Further, students might choose to participate in study abroad programs outside of their primary discipline, thus depriving themselves of valuable domain-specific experiences.

The concept of "internationalization at home" (IaH) broadly encompasses internationally-related activities — both curricular and co-curricular — sponsored by a university [10]. The definition is extremely wide-ranging, and is often interpreted quite differently in different regions of the world or the context of the institution [11]. Quantitative self-reported survey data examined by researchers Soria and Troisi indicate that student GII competencies are positively influenced by a wide variety of $\mathrm{IaH}$ activities (including internationallythemed academic coursework), and, in some cases, may even prove more effective at improving GII competencies than study abroad participation [12, p. 273]. We believe that this data provides positive motivation for furthering study related to global collaborative experiences integrated into the classroom.

\section{Methodology}

A necessary factor in this study was the selection of a classroom project whose success was dependent on the student maintaining a global perspective and could be conducted in multiple classroom contexts. The authors were selected by the US Department of State Diplomacy Lab [13] to conduct a project entitled “'An App for That!' - Mobile app design for Antibiotic Lifecycle Mapping" [14, p. 94]. The project deliverable was the prototype of a mobile application's user interface that would allow citizen scientists to contribute data related to antibiotic contamination in the environment. The intersection of IT principles (user interface design and mobile application development) with the intended worldwide audience made this project an ideal choice.

The project was conducted in two semester-long undergraduate courses in the Computer and Information Technology program at IUPUI [15]. The first course, entitled "Visual Design for Software," asked students to collaborate on the project in small teams with no outside influence. The second course, "Global IT Management" included a one-week study abroad trip to Pune, India during the semester's spring break. Students in the second course had the opportunity to work directly with students at Symbiosis Centre for Information Technology in Pune [16] for two days of the visit. The same instructor worked with both sets of students throughout the duration of the project, and students in both courses were presented with the same collection of materials and reference works.

We developed a pre/post survey instrument that contained a mix of demographic and Likert-scale questions that inquired about students' perceptions of their global, international, and intercultural competencies. The preliminary survey was distributed prior to the introduction of the classroom project and the summary survey was distributed near the conclusion of the courses where the project was conducted.

Study participants were asked to rate their knowledge and capabilities in a variety of categories including globalization, technical issues in international settings, and teamwork and collaboration. Participants were also asked whether they agreed or disagreed with a number of statements related to their cultural awareness, confidence in understanding cultures other than their own, and interactions with people from different national or cultural backgrounds. The study instrument was based on previous studies conducted by the authors when working with collaborations between students from different countries during a study abroad experience [17].

\section{STUdy COHORT}

Although both courses are part of the same IT program, differences in the enrollments of the two courses must be considered. The Visual Design for Software course is required for 
all students in the major, whereas the Global IT Management course is an elective. Because of the study abroad component, the Global IT course is far more expensive than other courses in the program. 32 students were enrolled in the Visual Design course (21 participated in the study), and 14 students enrolled in the Global IT course (12 participated in the study.)

It is not surprising that students interested in a study abroad program might already possess heightened global competencies. Students in this group showed consistently higher indications of GII competencies in the preliminary survey than did their counterparts in the local course. Table I provides the preliminary self ratings for both groups (on a scale of 1-5) in the following measures:

A Confidence to work in an international company or overseas

B Ability to communicate effectively with international audiences

C I have many friends from different cultures

TABLE I

PRELIMINARY RATINGS IN GII MEASURES

\begin{tabular}{|c|c|c|c|}
\hline Course & $\boldsymbol{A}$ & $\boldsymbol{B}$ & $\boldsymbol{C}$ \\
\hline Visual Design (Local) & 3.30 & 3.42 & 3.68 \\
\hline Global IT (Study Abroad) & 3.91 & 3.90 & 4.36 \\
\hline
\end{tabular}

Also of note is that the group of study abroad students tended to rate themselves lower in technical competencies in a global perspective than students in the local course. Table II contains the preliminary self ratings for both groups (on a scale of 1-5) in the following measures:

A Understanding of issues in a globalized IT environment

B Knowledge of issues that impact IT on a global scale

TABLE II

Preliminary Ratings in Global IT Measures

\begin{tabular}{|c|c|c|}
\hline Course & $\boldsymbol{A}$ & $\boldsymbol{B}$ \\
\hline Visual Design (Local) & 3.45 & 3.50 \\
\hline Global IT (Study Abroad) & 3.08 & 3.00 \\
\hline
\end{tabular}

Preliminary results indicate that although the two groups of students were distinct in certain factors, many similarities between the populations were observed. Students in both courses rated themselves nearly equally when asked about their "recognition of the need (to) engage in a globalized IT environment" and their "ability to apply knowledge of IT appropriate to an international setting." The self-selected nature of participants in the Global IT program was detectable, but not extraordinary.

\section{Results}

Of 35 total measures, students in the Global IT course increased their self-reported ratings in 32 categories. Students in the local Visual Design course with no international collaboration rated themselves more highly in just 19 categories and some by a very negligible amount.
As expected, metrics related to collaboration with individuals from a different country led to starkly different outcomes between the local course and the study abroad course most likely owing to the lack of exposure to international team members by the students in the local course. When asked about their "...understanding of technical barriers when working with people from different countries," students in the study abroad course demonstrated a $20.93 \%$ higher self-rating whereas students in the local course demonstrated a negligible decrease (Table III).

TABLE III

UNDERSTANDING OF TECHNICAL BARRIERS

\begin{tabular}{|c|c|c|c|}
\hline Course & Prelim. & Summary & Difference \\
\hline Visual Design (Local) & 3.60 & 3.41 & $-5.23 \%$ \\
\hline Global IT (Study Abroad) & 3.58 & 4.33 & $20.93 \%$ \\
\hline
\end{tabular}

Similarly, students in the study abroad course reported a much higher "...(confidence) in my ability to work with international team members..." (Table IV).

TABLE IV

CONFIDENCE With INTERNATIONAL TEAm MEMbers

\begin{tabular}{|c|c|c|c|}
\hline Course & Prelim. & Summary & Difference \\
\hline Visual Design (Local) & 3.68 & 3.88 & $5.38 \%$ \\
\hline Global IT (Study Abroad) & 4.09 & 4.78 & $16.79 \%$ \\
\hline
\end{tabular}

Of some concern was the fact that students in the local group did not appear to make many improvements in their understanding and knowledge of domain-specific issues related to the technical requirements of the project. For example, one assessment measure asked students to rate themselves on their "...understanding of professional, ethical, legal, security and social issues in the globalized information technology environment" (Table V) and revealed that students in the local group saw a decrease in their rating while the study abroad students appeared to reap some gains.

TABLE V

UNDERSTANDING OF ISSUES IN GLOBALIZED IT ENVIRONMENT

\begin{tabular}{|c|c|c|c|}
\hline Course & Prelim. & Summary & Difference \\
\hline Visual Design (Local) & 3.45 & 3.35 & $-2.81 \%$ \\
\hline Global IT (Study Abroad) & 3.08 & 3.67 & $18.92 \%$ \\
\hline
\end{tabular}

In another example, the study abroad students again outperformed the local students when asked about their "...knowledge of current issues that impact information technology on a global scale" (Table VI).

TABLE VI

KNOWLEdGe of CURRENT ISSUES IN IT ON GLobal SCALE

\begin{tabular}{|c|c|c|c|}
\hline Course & Prelim. & Summary & Difference \\
\hline Visual Design (Local) & 3.50 & 3.41 & $-2.52 \%$ \\
\hline Global IT (Study Abroad) & 3.00 & 3.67 & $22.22 \%$ \\
\hline
\end{tabular}


Finally, students were asked to rate their "...knowledge about the development of information technology in a region of the world beyond your home country" (Table VII). As previously demonstrated, students in the study abroad course tended to rate their initial disciplinary expertise somewhat lower than the local students in both measures - yet they reported improved values that exceeded those of the local (and originally more confident) students at the conclusion of the project.

TABLE VII

Knowledge of DeVelopment of IT OUtSide of Home Country

\begin{tabular}{|c|c|c|c|}
\hline Course & Prelim. & Summary & Difference \\
\hline Visual Design (Local) & 3.30 & 3.35 & $1.60 \%$ \\
\hline Global IT (Study Abroad) & 3.17 & 3.89 & $22.81 \%$ \\
\hline
\end{tabular}

\section{DISCUSSION}

The disparity in self-reported improvements between the local group and study abroad group is not surprising and supports the notion that the impact of study abroad experiences is both positive and substantial. The results indicate, however, that the global context of the project introduced into the courses had a negligible impact on students who worked without any international collaboration. This is perhaps the most disappointing result of this study and indicates that the introduction alone of globally-themed projects may not be enough to significantly boost the global, international, and intercultural (GII) competencies of students.

The improved GII competency ratings reported by the study abroad students could be explained by multiple phenomena - and most likely a combination of more than one. First, as demonstrated, the self-selected nature of the study abroad course most likely attracts students who generally have a more open-minded attitude toward exploring and improving their GII competencies. Second, conducting the project firsthand in a foreign country could provide the students an explicit shift in perspective that requires them to consider environments other than those with which they are already familiar. A third possibility is that the collaboration with their international peers afforded students the opportunity to refine and reject ideas in a more rapid and impactful fashion, as they were receiving immediate feedback throughout the collaboration. Any of these factors could explain the greater impact of the project on the students who participated in the study abroad program.

\section{CONCLUSION}

The results of this study demonstrate that globally-themed projects alone do not provide a demonstrable improvement in student global, international, and intercultural competencies. Such projects must be executed in such a way that the students are required to experience an environment (either physical or personal) that is foreign to them so that they can incorporate that additional perspective into the results of the project. In this instance, the external perspectives were provided to the study abroad group both in the experience of international travel as well as the opportunity to collaborate with peers from a foreign university. We hypothesize that either of those factors alone could support improved GII competencies, but the combination of the two will most likely have the broadest impact.

Therefore, the challenge of improving students' global competencies on a broad scale remains. Although study abroad programs show demonstrable impact, the highly selective nature and low rate of participation puts these gains out of reach for the vast majority of students. Global competencies are eagerly sought in the marketplace and can provide a substantial advantage to graduates with tangible experience. It is imperative that students be afforded opportunities to improve their GII competencies as part of their disciplinary studies.

\section{FUTURE WORK}

A body of research related to "virtual exchange" and similar endeavors is emerging. These programs allow students from different regions of the globe to collaborate on projects using Information and Communication Technologies (ICT.) The concept of virtual exchange could afford students the opportunity to collaborate on a discipline-specific project without the rigor and cost of studying abroad. It is expected that the impact of such an opportunity will impart a greater positive impact on student GII competencies than a classroom project alone, yet perhaps not quite as much as that of a traditional study abroad program. The potential benefit of a virtual exchange is that it can be made accessible to all students in any given course in the discipline instead of reserved for the select few who are willing and able to participate in a study abroad.

However, there are few examples of such work specific to a STEM program and little information about the impact it has on the students remaining coursework and the ability to leverage the experience into employment after graduation. Many universities - including IUPUI - have created socalled "global classrooms" and other similar support initiatives to encourage faculty and students at distant universities to collaborate [18], [19], [20], [21]. Few examples of these types of exchanges in STEM disciplines exist - and it is rare to find a study that describes this type of experience in a course required by all students in a particular program. Therefore, the populations of students who have engaged in a virtual exchange is still somewhat selective.

We intend to use virtual exchange opportunities to continue our work related to improving student GII competencies and are actively seeking partners who would be willing to participate in such a program, particularly in disciplines that are complimentary to projects with an IT perspective.

\section{ACKNOWLEDGMENT}

The authors would like to acknowledge the support of the STEM Education Innovation and Research Institute at IUPUI for their ongoing support and funding for this project. 


\section{REFERENCES}

[1] E. Egron-Polak and R. Hudson, Internationalization of Higher Education: Growing expectations, fundamental values. IAU 4th Global Survey. International Association of Universities, Apr. 2014, ISBN: 978-92-9002-2015. [Online]. Available: https://iau-aiu.net/IMG/pdf/iau4th - global - survey - executive - summary.pdf (accessed 04/15/2018).

[2] IUPUI Study Abroad Office, "CIT Student Study Abroad Participation," Unpublished raw data, 2018.

[3] COIL. [Online]. Available: http : / / coil . suny . edu/ (accessed 04/10/2020).

[4] UNICollaboration. [Online]. Available: https://www. unicollaboration.org/ (accessed 06/22/2020).

[5] European Association for International Education, en, Library Catalog: www.eaie.org. [Online]. Available: https://www.eaie.org (accessed 06/22/2020).

[6] Z. Qiang, "Internationalization of higher education: Towards a conceptual framework," Policy Futures in Education, vol. 1, no. 2, pp. 248-270, Jun. 2003, ISSN: 1478-2103. DOI: 10.2304/pfie.2003.1.2.5.

[7] D. K. Deardorff, "Identification and assessment of intercultural competence as a student outcome of internationalization," Journal of Studies in International Education, vol. 10, no. 3, pp. 241-266, Sep. 2006, ISSN: 1028-3153. DOI: $10.1177 / 1028315306287002$.

[8] T. R. Williams, "Exploring the impact of study abroad on students' intercultural communication skills: Adaptability and sensitivity," Journal of Studies in International Education, vol. 9, no. 4, pp. 356-371, Dec. 2005, ISSN: 1028-3153. DOI: $10.1177 / 1028315305277681$.

[9] H. T. Black and D. L. Duhon, "Assessing the impact of business study abroad programs on cultural awareness and personal development," Journal of Education for Business, vol. 81, no. 3, pp. 140-144, Feb. 2006, ISSN: 08832323.

[10] P. Crowther, M. Joris, M. Otten, B. Nilsson, H. Teekens, and B. Wächter, Internationalisation at home: a position paper. European Association for International Education, 2000, ISBN: 978-90-74721-16-5.

[11] H. Watkins and R. Smith, "Thinking globally, working locally: Employability and internationalization at home," Journal of Studies in International Education, p. 102831531775168 , Jan. 2018, ISSN: 1028-3153, 1552-7808. DOI: $10.1177 / 1028315317751686$.

[12] K. M. Soria and J. Troisi, "Internationalization at home alternatives to study abroad: Implications for students' development of global, international, and intercultural competencies," Journal of Studies in International Education, vol. 18, no. 3, pp. 261-280, Jul. 2014, ISSN: 1028-3153. DOI: $10.1177 / 1028315313496572$.

[13] US Department of State Diplomacy Lab. [Online]. Available: http : / / diplomacylab . org/ (accessed 05/09/2018).
[14] Diplomacy Lab Spring 2018 Project Menu, 2018. [Online]. Available: http://diplomacylab.org/wp-content/ uploads / 2017 / 10 / Spring - 2018 - Project - Menu . pdf (accessed 05/10/2018).

[15] CIT. [Online]. Available: https : / / et . iupui . edu / departments / cigt / programs / cit/index . html (accessed 06/22/2020).

[16] Symbiosis Centre for Information Technology. [Online]. Available: https://www.scit.edu/ (accessed 06/22/2020).

[17] R. Elliott and X. Luo, "Improving the Global, International and Intercultural (GII) Competencies of IT Students via Integrated Collaboration During Study Abroad," in Proceedings of the 19th Annual SIG Conference on Information Technology Education, ser. SIGITE '18, New York, NY, USA: ACM, 2018, pp. 50-55, ISBN: 978-1-4503-5954-2. DOI: 10 . 1145 / 3241815 . 3241858. [Online]. Available: http://doi.acm.org/10. 1145/3241815.3241858 (accessed 11/16/2018).

[18] DePaul University Global Learning Experience, 2020. [Online]. Available: https : / / resources . depaul . edu / teaching - commons / programs / Pages / global - learning experience.aspx (accessed 04/10/2020).

[19] Drexel University Global Classroom. [Online]. Available: http://drexel.edu/oip/academics/global-classroom/ (accessed 04/10/2020).

[20] Global Classrooms - Global Maryland, University of Maryland. [Online]. Available: https://globalmaryland. umd . edu / content / global - classrooms (accessed 04/10/2020).

[21] Videoconferencing Classroom: Global Learning: Office of International Affairs: Indiana University-Purdue University Indianapolis, 2018. [Online]. Available: http: / / international . iupui . edu / global - learning / video classroom/index.html (accessed 04/10/2020). 